\title{
The Research on Servo Control System for AC PMSM Based on DSP
}

\author{
BaiLei $^{1, a}$, Wengang Zheng ${ }^{2, b}$ \\ ${ }^{1}$ Engineering Training Center, Beihua University, Jilin Province, 132020, \\ People's Republic of China
}

${ }^{2}$ College of Mechanica Engineering, Beihua University, Jilin Province,132020, People's Republic of China

aemail: 82295856@qq.com, ${ }^{\mathrm{b} e m a i l}$ :985304275@163.com

Keywords: PMSM; DSP; AC Servo System

\begin{abstract}
This paper use the digital signal processor (DSP) TMS320LF2407A control chip is adopted as core of the control system. Three closed loop of the controller, namely electricity, speed and displacement, were designed. Using space voltage vector pulse wide modulation technology (SVPWM), constructed a servo system of permanent magnet synchronous motor(PMSM) based on DSP. Through debugging the software on the MATLAB platform, the algorithm of three loops has been verified.
\end{abstract}

\section{Introduction}

PMSM AC servo system is a kind of new-style AC servo system which consists of PMSM, modern electronic technique and control technique. Because of its good performance, it has become one of research hotspots in electric drive of the time ${ }^{[1]}$. Make a spurt of progress of development of modern control technology promoted the rapid development of servo system of permanent magnet synchronous motor. Especially the development of digital signal processor and power electronic technology, provides the conditions for the realization of high performance digital system ${ }^{[2]}$. Higher tracking response, accuracy, reliability, robustness and flexibility of system, are the new target of the development of PMSM system.

At present, the permanent magnet synchronous motor servo control system is still widely using the traditional PID controller. However, PMSM servo system is a complex system, has time-varying, strong coupling and nonlinear. In addition the system in the running process, will be affected by uncertain factors, such as load changes. System parameters and model structure will change along with the environment change. Therefore, the use of conventional PID controller is not easy to obtain good control effect. In view of the above question, select the appropriate control strategy has become the key to increase the performance of servo system ${ }^{[3]}$.

\section{PMSM vector control technology}

PMSM vector control model.

Ignore the harmonics saturation, eddy current of motor and hysteresis loss, based on the Clark transform and Park

$$
P\left[\begin{array}{c}
i_{d} \\
i_{q} \\
\omega_{m}
\end{array}\right]=\left[\begin{array}{ccc}
-\frac{R_{a}}{L} & P_{n} \omega_{m} & 0 \\
-P_{n} \omega_{m} & -\frac{R_{a}}{L} & -\frac{P_{n} \psi_{f}}{L} \\
0 & P_{n} \psi_{f} & 0
\end{array}\right]\left[\begin{array}{c}
i_{d} \\
i_{q} \\
\omega_{r}
\end{array}\right]+\left[\begin{array}{c}
\frac{U_{d}}{L_{a}} \\
\frac{U_{q}}{L_{a}} \\
\frac{-T_{L}}{J}
\end{array}\right]
$$

PMSM is a multivariable control system. Because $i_{d}$ and $i_{q}$ have coupling relationship, $i_{d}$ 、 $i_{q} 、 \omega_{r}$ can not be independent of the adjustment, which makes the system cannot linearization control. Using $i_{d}=0$ control scheme, solves the problem[4]. 


\section{SVPWM algorithm.}

1) Determine the section of vector $U_{\text {out }}$

The following transformations on $U_{\alpha}$ and $U_{\beta}$ :

$$
\left\{\begin{array}{l}
U_{a}=U_{\beta r e f} \\
U_{b}=\frac{\left(\sqrt{3} U_{\text {oref }}-U_{\beta r e f}\right)}{2} \\
U_{c}=\frac{\left(-\sqrt{3} U_{\text {oref }}-U_{\text {pref }}\right)}{2}
\end{array}\right.
$$

According to the calculation formula, get the polarities of $U_{\alpha}, U_{\beta}$ and $U_{c}$. Determine the section of output reference voltage.

2) Calculation of $T_{1}, T_{2}$

For the calculation of and, introduces three common variables, as follows:

$$
\left\{\begin{array}{l}
X=\sqrt{3} U_{\beta r e f} T / U_{D C} \\
Y=\left(3 U_{\text {oref }}+\sqrt{3} U_{\beta r e f}\right) T / 2 U_{D C} \\
Z=\left(-3 U_{\text {oref }}+\sqrt{3} U_{\text {Bref }}\right) T / 2 U_{D C}
\end{array}\right.
$$

According to the calculation of the resulting $X, Y, Z$, to determine the basic vector space time $\left(T_{1} 、 T_{2}\right)$ by querying the table transform of permanent magnet synchronous motor, the mathematical model can be written as:

Able 1 Section query table

\begin{tabular}{|c|c|c|c|c|c|c|}
\hline section & 1 & 2 & 3 & 4 & 5 & 6 \\
\hline $\mathrm{T}_{1}$ & $\mathrm{Z}$ & $\mathrm{Y}$ & $-\mathrm{Z}$ & $\mathrm{X}$ & $-\mathrm{X}$ & $-\mathrm{Y}$ \\
\hline $\mathrm{T}_{2}$ & $\mathrm{Y}$ & $-\mathrm{X}$ & $\mathrm{X}$ & $\mathrm{Z}$ & $-\mathrm{Y}$ & $-\mathrm{Z}$ \\
\hline
\end{tabular}

3) Calculation of voltage vector switching point

Get the vector turn-on time of $T_{1}$ and $T_{2}$, calculate the three-phase power device turn-on switching time.

$$
\left\{\begin{array}{l}
T_{\text {aon }}=\left(T-T_{1}-T_{2}\right) / 4 \\
T_{\text {bon }}=T_{\text {aon }}+T_{1} / 2 \\
T_{\text {con }}=T_{\text {bon }}+T_{2} / 2
\end{array}\right.
$$

Then according to querying the table2, determining the driving time of three-phase voltage inverter, space vector output can achieve any angle[5].

Table 2 Different sections conduction time table

\begin{tabular}{|c|c|c|c|c|c|c|}
\hline section & 1 & 2 & 3 & 4 & 5 & 6 \\
\hline $\mathrm{T}_{\mathrm{cm} 1}$ & $\mathrm{~T}_{\text {bon }}$ & $\mathrm{T}_{\text {aon }}$ & $\mathrm{T}_{\text {aon }}$ & $\mathrm{T}_{\text {con }}$ & $\mathrm{T}_{\text {con }}$ & $\mathrm{T}_{\text {bon }}$ \\
\hline $\mathrm{T}_{\mathrm{cm} 2}$ & $\mathrm{~T}_{\text {aon }}$ & $\mathrm{T}_{\text {con }}$ & $\mathrm{T}_{\text {bon }}$ & $\mathrm{T}_{\text {bon }}$ & $\mathrm{T}_{\text {aon }}$ & $\mathrm{T}_{\text {con }}$ \\
\hline $\mathrm{T}_{\mathrm{cm} 3}$ & $\mathrm{~T}_{\text {con }}$ & $\mathrm{T}_{\text {bon }}$ & $\mathrm{T}_{\text {con }}$ & $\mathrm{T}_{\text {aon }}$ & $\mathrm{T}_{\text {bon }}$ & $\mathrm{T}_{\text {aon }}$ \\
\hline
\end{tabular}

\section{The Hardware Circuit Design}

The hardware circuit of the PMSM servo control system is the main part of: power board, high speed DSP control board, power board. Among them, each part separately contain different functions of the hardware part. The system used TMS320LF2407A as the main control chip DSP. In the system, the power supply board includes: rectifier circuit and filter current limiting circuit; 
The DSP control board mainly includes: DSP, off chip memory, SPI/SCI interface circuit plate, reset and clock circuit; The power driver board consists of a three-phase bridge inverter circuit, current protection circuit, current driving voltage protection circuit. This system is a three closed loop control system, includes: displacement loop, speed loop, current loop. According to the speed feedback signal, can draw the position feedback signal. Displacement feedback signal, the feedback of speed and current feedback signal will be input into the DSP, through the reasonable control algorithm, get the SPVWM driving signal. After the photoelectric isolation, by the drive circuit to drive the six IGBT, thereby driving three-phase sine wave permanent magnet synchronous motor objective. By the detection circuit, motor status can be displayed online monitoring module. When the current is over-current, or overheating, or short circuit, or overvoltage, DSP will interrupt the PWM control signal, the motor will stop running state.

\section{The Software Design of the System}

PMSM vector control system structure is shown in figure 1, the input of the system, is the speed instruction signal and the difference between the actual value of the speed feedback signal, the fuzzy self tuning PI controller's output value as the reference current value. After the current sensor in measuring the current values of PMSM, through Clark transform and Spark transform, the system achieved the current feedback signal. The deviation between the reference current value and the feedback current value, through the conventional PI control, get the reference voltage value. Through the implementation of SVPWM technology in the software, realize the variable frequency speed control of PMSM.

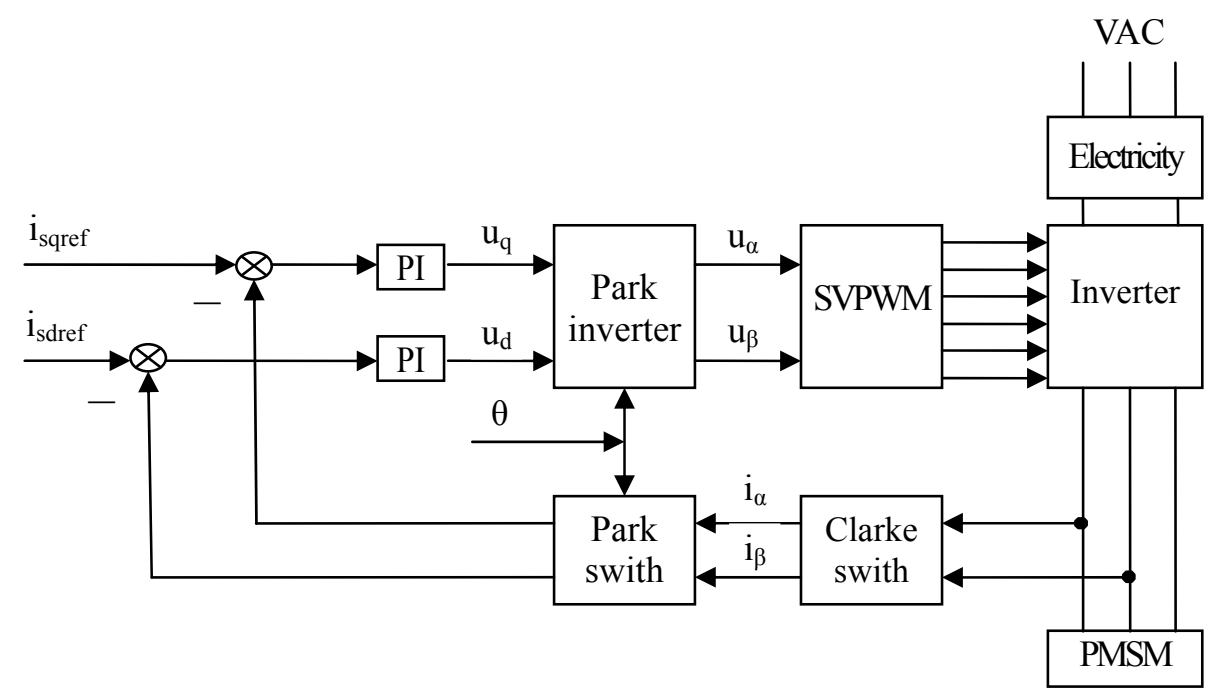

Figure. 1 Field oriented vector control system structure diagram

\section{The Simulation Results and Analysis}

Using MATLAB Simulink simulation software as a development tool, used to realize the modeling and Simulation of dynamic systems. The main modules include: speed control module, current regulation module, voltage transformation module, SVPWM module, current transformation module, motor and its measurement module.

In the simulation model, the initial reference speed is set to $300 \mathrm{rad} / \mathrm{s}(2865 \mathrm{r} / \mathrm{min})$. In $0.02 \mathrm{~s}$, the reference speed jumps to $200 \mathrm{rad} / \mathrm{s}(1910 \mathrm{r} / \mathrm{min})$. The system load using step module input, in the stage of $0 \sim 0.05 \mathrm{~s}$, the system load torque is changed to $0.5 \mathrm{~N} \cdot \mathrm{m}$. The whole simulation process, the motor speed, torque and current's waveforms are shown in Figure 2, figure 3 and figure 4. 


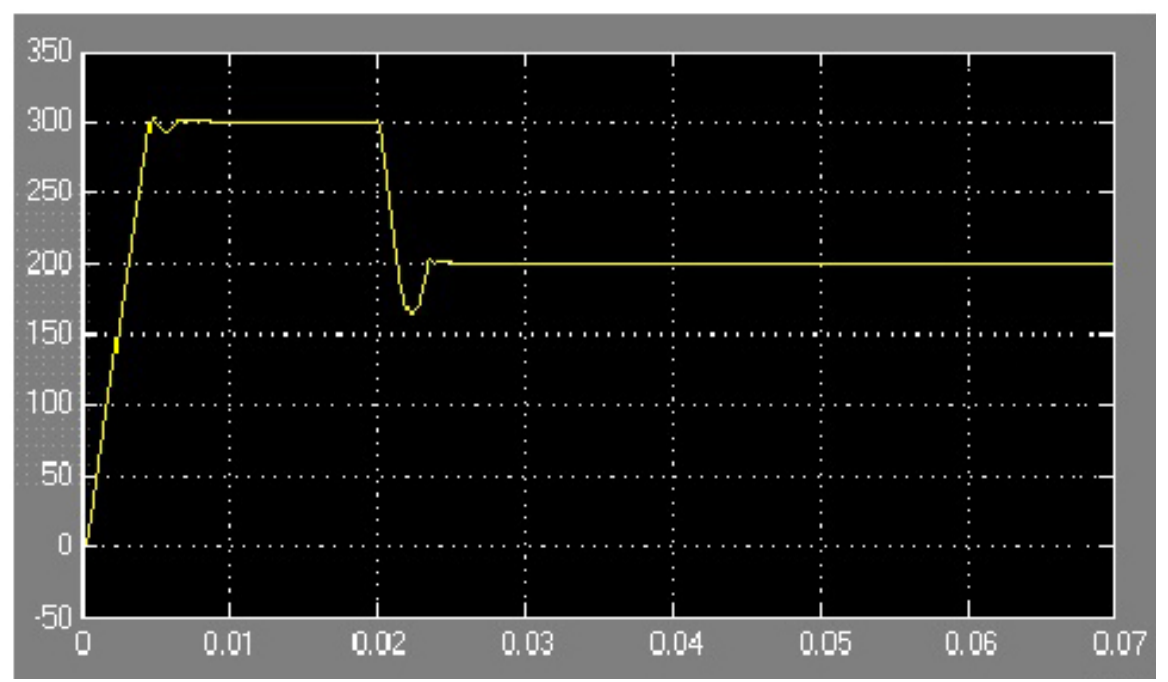

Figure. 2 Field oriented vector control system structure diagram

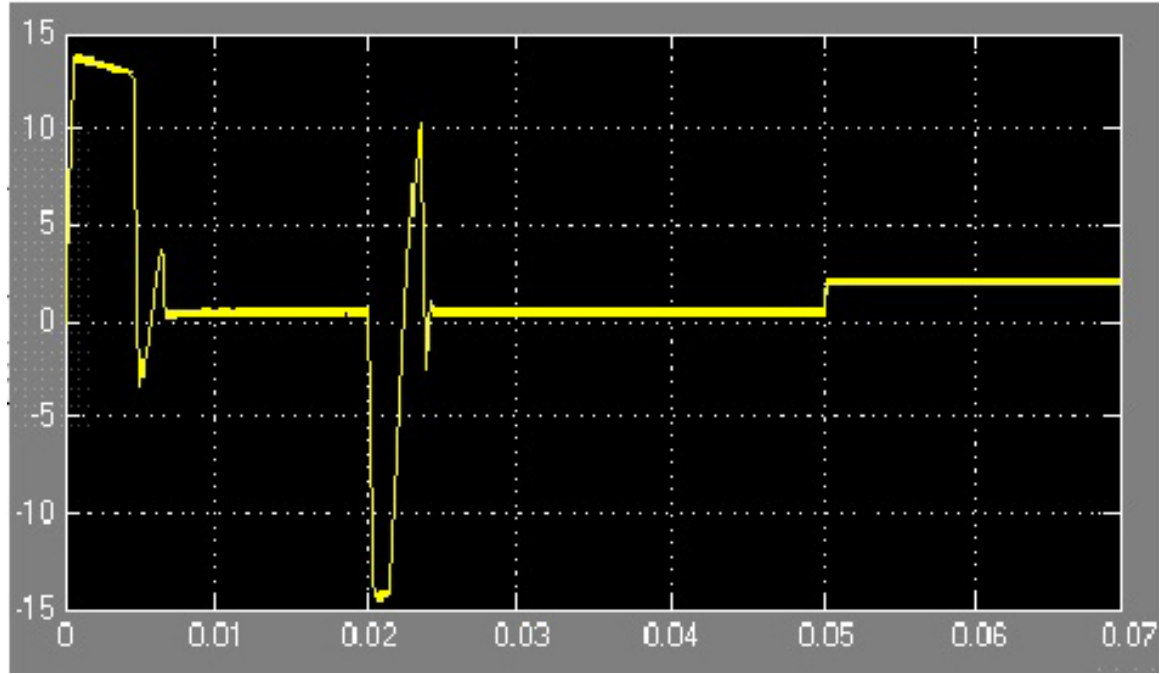

Figure.3 Field oriented vector control system structure diagram

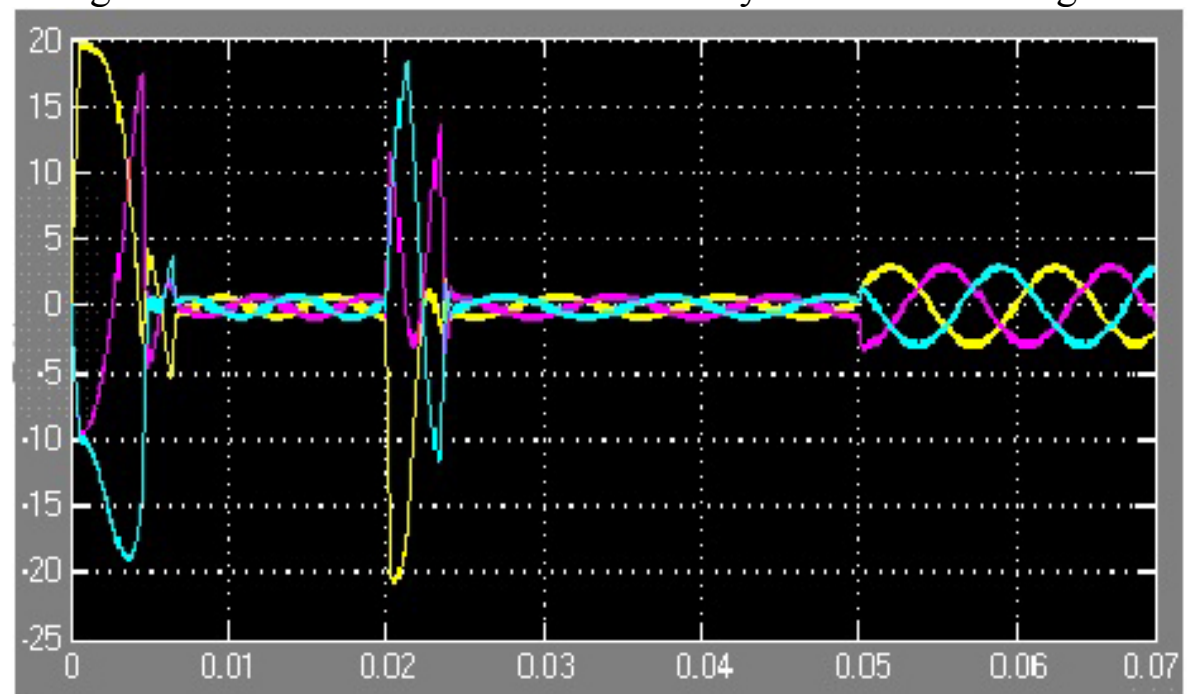

Figure.4 Field oriented vector control system structure diagram

From Figure 2 we can see, when the motor is started, the fast response speed of step signals order is $300 \mathrm{rad} / \mathrm{s}$, a steady state is reached. When reducing speed, it can also quickly speed tracking response. However in $0.05 \mathrm{~s}$, the waveform has some slight fluctuations, and then to achieve stable operation quickly. It can be seen from Figure 3, along with the load increasing, the three-phase current is increasing constantly. Figure 4 shows, the current loop of system played a very important role, motor speed to the new equilibrium point with the maximum torque, the whole simulation system has fast response and stability. 


\section{Conclusion}

This article first analyzes the SVPWM space vector control principle, then determines the $i_{d}=0$ control method, simulation model is built based on DSP system, and has carried on the simulation using MATLAB/Simulink. The experimental results show that the effect is good, and prove the validity of the algorithm, realized the digital control system request.

\section{References}

[1] Aimeng Wang, Heming Li, Pengwei Sun, etal. DSP-based Fied Oriented Control of PMSM using SVPWM In Radar Servo System. [c].proceeding of 2005 IEEE International Conference on Electric Machines and Drives.2005,486-489

[2]R. LESSMEIER etc. Microprocessor-Controlled AC-Servo Drives with Synchronous or Induction motors: which is preferable. IEEE TRANSACTIONS ON INDUSTRY APPLICATIONS, 1986.VOLIA-22.No.5.SEP/DCT.

[3]Shi KL, Chan TF. Speed Estimation of an Induction Motor Drive Using an Optimized Extended Kalman Filter. IEEE Trans on Industry Electronics,2002(49):124-133

[4]Wang J S, Lee CSG. Self adaptive Recurrent Neuro-fuzzy Control of an Automous Under water Vehicle. IEEE Transactions on Robotics and Automation, 2003, 19(2):283-295.

[5]Sheng Zhao, Xiafu Peng. A Modified Direct Torque Control Using Space Vector Modulation(DTC-SVM)for Surface Permanent Magnet Synchronous Machine(PMSM)with Modified 4-order Sliding Mode Observer [J]. International Conference on Mechatronics and Automation, 2007, 1207-1212. 